MARE SURE THE JOURNAL REACHES YOU

This is the last issue of the ICCA Journal to appear in 1984. Your meembership has formally expired by December 31, 1984. In 1984, you should have recelved four ICCA Journals, which were your due under your membership.

In order to receive the 1985 Journals, you should renew your membership (new applications are welcome too). On the initiative of ICCA's President, the (renewal) fee is now US \$10.-- plus a US \$ 5.-- surcharge, pending approval by the 1986 Triennial Meeting.

For renewals or new subscriptions, US and Canadian readers are therefore invited to remit US \$ 15.-- for 1985 to:

ICCA

c/o W. Blanchard

Mid-America Federal Saving

Bank no. 271971560 Naperville

Account no. 600132099.

European readers are invited to remit $\mathrm{Hfl}$. 45.-- (or the equivalence in convertible currency) to:

\title{
ICCA-Europe
}

c/o H.J. van den Herik

AMRO-Bank no. 450790878

Mekelweg / Christiaan Huygensweg Postbus 300,2600 AH DELFT, The Netherlands

The Postgiro account no. of the AMBRO-Bank is 460175

Please include a correct statement of your mailing address. (We keep receiving payments without addresses! Several of these puzzles are not solved yet.) Moreover, we remark that Banking fees are not included in the \$15.-(or Hf1. 45.--) subscription. Should your mailing label be erroneous or when changing residence, please return an amended label to Mr. Blanchard or Mr. Van den Herik as the case may require.

Those not resident in Europe, the U.S. or Canada, are at liberty to remit their dues to either account. However, they are encouraged to use the European account, resulting in their Journals being sent directly from Delft (The Netherlands), which may make for speedier delivery. 


\section{ADDRESSES OF AUTHORS}

David J. Slate

Vogelback Computing Center

Northwestern University

Evanston, IL 60201 / U.S.A.

Kenneth Thompson

Bel1 Telephone Labs, Room 2C423

600 Mountain Avenue, Murray Hill

New Jersey 07974 / U.S.A.

Göran Grottling

Diabasvägen 3

S 43700 Lindome / Sweden
Dr. A.N. Walker

Department of Mathematics

University of Nottingham

Nottingham NG7 2RD / U.K.

Tim Breikreutz/Jonathan Schaeffer

Dept. of Computing Science

University of Alberta

Edmonton, Alberta T6C 2H1 / Canada

Drs. J.J. van Oosterwijk Bruyn

Hilversumseweg 6

1251 EX Laren / The Netherlands

The addresses of contributors not mentioned above are published elsewhere in the Journal.

Contributions (up to 4000 words) should be typed double spaced;

chess diagrams when helpful should be included;

all notation must be algebraic, with $\mathrm{N}$ for Knight.

Short contributions (2000-3000 words) are preferred.

Longer papers of striking originality and cogency may be considered,

provided the authors consent to publication in instalments.

Please submit all contributions and correspondence to:

Dr. H.J. van den Herik

Delft University of Technology

Department of Mathematics and Informatics

Julianalaan 132 / Room 2.115

2628 BL DELFT / The Netherlands

Deadline for copy for the next issue is March 1, 1985.

Please address all material to be reviewed, digested or abstracted to:

Professor T.A. Marsland

University of Alberta

Department of Computing Science

- Edmonton, Alberta T6G 2H1

CANADA 